\title{
A Meteorology Based Particulate Matter Prediction Model for Megacity Dhaka
}

\section{Aerosol and Air Quality} Research

\section{OPEN ACCESS}

Received: July 3, 2020

Revised: October 1, 2020

Accepted: October 13, 2020

\section{${ }^{*}$ Corresponding Author:}

mislam7@ncsu.edu

${ }^{+}$These authors contributed equally to this work

\section{Publisher:}

Taiwan Association for Aerosol Research

ISSN: $1680-8584$ print

ISSN: 2071-1409 online

Copyright: The Author(s). This is an open access article distributed under the terms of the Creative Commons Attribution License (CC BY 4.0), which permits unrestricted use, distribution, and reproduction in any medium, provided the original author and source are cited.

\author{
Sadia Afrin ${ }^{1,2+}$, Mohammad Maksimul Islam ${ }^{1,2^{*}}$, Tanvir Ahmed ${ }^{1}$ \\ ${ }^{1}$ Department of Civil Engineering, Bangladesh University of Engineering and Technology, Dhaka \\ - 1000, Bangladesh \\ 2 Department of Civil, Construction, and Environmental Engineering, North Carolina State \\ University, 2501 Stinson Dr, Raleigh, NC 27695, USA
}

\section{ABSTRACT}

Dhaka, the capital of Bangladesh, is one of the megacities in the world with the worst air quality. In this study, we develop statistical models for predicting particulate matter (PM) concentration in ambient air of Dhaka using meteorological and air quality data from 2002 to 2004 of a continuous air quality monitoring station (CAMS). Model for finer fraction of PM (PM 2.5 ) explains up to $57 \%$ variability of daily $\mathrm{PM}_{2.5}$ concentration, whereas model for coarser fraction $\left(\mathrm{PM}_{2.5-10}\right)$ explains up to $35 \%$ of its variability, indicating that $\mathrm{PM}_{2.5}$ is influenced more by meteorology than PM 2.5-10. Temperature, wind speed, and wind direction account for $94 \%$ of total $\mathrm{PM}_{2.5}$ variability explained by the model, while relative humidity contributes to $75 \%$ of total $\mathrm{PM}_{2.5-10}$ variability. Inclusion of PM lag effect increases models' predictive power by $4-16 \%$. In general, our developed models show promising performance in capturing the seasonal variability of Dhaka's PM concentration, although overestimate the low concentrations during wet season (April-September). We validate these models using a recent dataset (2013-2017) from the same monitoring site, in which modeled PM show strong positive correlations with observed concentrations ( $r=0.81$ and 0.76 for $\mathrm{PM}_{2.5}$ and $\mathrm{PM}_{2.5-10}$ respectively). Models also exhibit strong predictive power in forecasting PM levels of two other CAMSs in Dhaka. Thus, the developed models have potentials to explain the temporal and spatial variability of daily PM within Dhaka. These models can be helpful to policymakers as they can predict daily PM at any location of Dhaka with reasonable accuracy if daily meteorological data and previous day's PM concentration are available. The effect of climate change scenarios on air pollution dynamics of Dhaka can also be assessed using these models.

Keywords: Air quality, Particulate matter, Regression model, Seasonal variability

\section{INTRODUCTION}

Air pollution is the dominant driver of global mortality according to the 'Global Burden of Disease' study (Cohen et al., 2017). Every year, outdoor and indoor air pollution attributes to around 8 million premature deaths globally (WHO, 2016). Especially particulate matter (PM)the most health-damaging air pollutant-has been found to be strongly associated with negative health outcomes (Bae and Hong, 2018). PM shows a strong positive association with all-cause mortality (Choi et al., 2009), respiratory morbidity, and possibly cardiovascular mortality and morbidity (Thurston et al., 2016). $\mathrm{PM}_{2.5}$ (particles with an aerodynamic diameter less than $2.5 \mu \mathrm{m}$ ) is also a big concern in ambient air in Bangladesh as evidenced by various observations spanning over several decades (Rahman et al., 2019). Observations since 1990 show that the population of this country has been exposed to $\mathrm{PM}_{2.5}$ levels above all three interim targets of the World Health Organization (WHO), making it one the countries with the highest $\mathrm{PM}_{2.5}$ exposures (Health Effects Institute, 2019). Thus, ambient $\mathrm{PM}_{2.5}$ has become one of the top risk factors affecting cardiovascular morbidity and mortality in Bangladesh (Islam et al., 2017). Each year, air pollution causes 195,000 premature deaths here (Rahman et al., 2019). PM2.5-attributed annual 
mortality in Bangladesh is also increasing over time and has been increased by $52 \%$ in the last two decades (Health Effect Institute, 2017).

The air pollution problem in Bangladesh is mostly concentrated in the urban cities of the country (Hossain et al., 2019). Among the major urban cities, air pollution in Dhaka, the capital of Bangladesh, is most concerning since it is one of the most densely populated cities in the world. Dhaka is ranked as the third most polluted megacities (Rahman et al., 2019) and the second most polluted capital in terms of poor air quality (IQAir, 2018). The huge population of the city ( 9 million) is constantly exposed to a high concentration of $\mathrm{PM}_{2.5}$ and $\mathrm{PM}_{10}$ (particles with an aerodynamic diameter less than $10 \mu \mathrm{m}$ ) for many years (Begum et al., 2013; Majumder et al., 2019). Both $\mathrm{PM}_{2.5}$ and $\mathrm{PM}_{10}$ in Dhaka frequently exceed the Bangladesh National Ambient Air Quality Standard (NAAQS) and the U.S. NAAQS (Hossain and Easa, 2012), causing a great health concern. A recent study by Tasmin et al. (2019) found an association of short-term exposure to PM with worsening of lung function of school children in Dhaka. Maji et al. (2018) also estimated $9051 \mathrm{PM}_{2.5}$ attributed deaths in Dhaka during the year 2016. The estimated economic costs of air pollution attributed to sickness and deaths in Dhaka by the World Bank are valued approximately US\$ 200-800 million per year (Afrin et al., 2012).

Brick kiln operations surrounding the city, fossil fuel combustion, industrial operation, vehicular emission, re-suspension of dust from unpaved roads and soil, construction works, and metal smelters are the primary sources of elevated PM concentration in Dhaka (Begum et al. 2010). Studies so far explored different aspects of air pollution in this city. Some studies focused on trend analysis of air pollutants (Rana et al., 2016a; Begum and Hopke, 2018), some explored the factors affecting seasonal variability of the air pollutants (Islam and Afrin, 2014; Islam et al., 2015), while several studies assessed the effectiveness of specific policies including the banning of "Two-Stroke Engines" and introduction of "Unleaded Gasoline" (Biswas et al., 2003; Begum et al., 2006). Some papers identified local sources by applying source apportionment techniques (Salam et al., 2008; Begum et al., 2010), while others highlighted the effect of transboundary sources (Rana et al., 2016a, b).

The elevated level of ambient PM concentration in Dhaka warrants initiatives to minimize the air pollution problem of the city. According to a World Bank report (World Bank, 2006), annually \$169-492 million could be saved by a $20 \%$ reduction in $\mathrm{PM}_{10}$ concentration in Dhaka. A recent report by "State of Global Air" (Health Effects Institute, 2019) shows that Bangladesh will gain the highest benefit in terms of life expectancy if it can meet the WHO guideline of $10 \mu \mathrm{g} \mathrm{m}^{-3}$ of $\mathrm{PM}_{2.5}$. An air quality prediction model could serve as an important policy tool to reduce the air pollution problem (Liang et al., 2015; Tong et al., 2019). Two basic types of models are used for air quality prediction-deterministic or chemical transport model (CTM) and empirical model. CTMs consider fundamental physics and chemistry of all possible emissions, and pollutant transport and transformation processes associated with air pollution. However, because of the huge complexities of CTM, uncertainties might arise from the assumptions considered while simulating pollutant concentration (Cobourn, 2010). Empirical or statistical models have also been used in some studies for air quality forecasting, assessing the effectiveness of adopted measures, and proposing possible measures of pollution reduction (Cobourn, 2010; Liu et al. 2012; Liang et al., 2015). Konovalov et al. (2009) found better performance of the empirical statistical model compared to CTM while forecasting PM 10 concentration.

In Dhaka, we do not have any unified, high-resolution, and time-varied emission information. Additionally, owing to the complexity and level of details required by a CTM, it is not always feasible to employ this modeling approach to develop a PM prediction model for Dhaka. Only one study so far has applied CTM to simulate pollutant concentrations in Dhaka (Azkar et al., 2012). However, owing to the unavailability of fine resolution emission inventory, the model greatly underestimated the observed pollutant concentrations. Since meteorology has been proved to be a significant driver of air quality worldwide (Tai et al., 2010; Pearce et al., 2011; Leung et al., 2017; Wang et al., 2019), a meteorology based statistical model (Cobourn, 2010) can be envisaged to forecast pollutant concentration in Dhaka. To our knowledge, no statistical/empirical model has been developed for Dhaka yet to predict PM concentration from meteorological inputs. Some studies explored the meteorology-air quality dynamics in Dhaka to different extents (Afrin et al., 2014; Islam et al., 2015, 2018; Kayes et al., 2019). Kayes et al. (2019) applied multiple linear and non-linear regression models to explore the role of three meteorological variables-temperature, 
relative humidity, and precipitation - on particulate and gaseous air pollutants. Islam et al. (2015) determined bivariate "Pearson correlation coefficient" between meteorological parameters and air pollutants. That study considered solar radiation and wind speed in addition to the other variables considered by Kayes et al. (2019). In addition, Islam et al. (2018) applied multilinear regression and a cross-correlation approach to assess the effect of meteorological parameters on seasonal variation of PM concentration in Dhaka. Although studies have shown that wind coming from the northwest direction of Dhaka during the winter months increases PM concentration (Islam et al., 2015; Mahmood et al., 2019), wind direction was not included as a predictor in the multilinear regression or correlation analysis in the above-mentioned studies.

In addition to the meteorological variables, the previous day's PM concentration (lag PM) has been identified as a significant predictor in the PM prediction model for different countries. Some studies considered the lag effect of PM concentration along with different matrices of fire smoke for estimating smoke-related PM2.5 (Price et al., 2012; Yao and Henderson, 2013), while Marsha and Larkin (2019) incorporated previous day's PM concentration for the development of statistical models for predicting ground-level $\mathrm{PM}_{2.5}$ prediction. Yao and Henderson (2013) identified lag $\mathrm{PM}_{2.5}$ as the most influencing predictor in their model predicting smoke-related $\mathrm{PM}_{2.5}$. Given the significance of PM lag effect, a PM regression model having the previous day PM as a predictor might have significant potential in explaining the daily variability of monitored PM concentration of Dhaka. However, modeling studies for Dhaka have not assessed the potential of this predictor in improving overall model performance.

Given the influence of meteorology over the air quality in Dhaka and the potential of meteorological parameters to predict pollutant concentration, we apply multivariate regression to develop a statistical predictive model for ambient PM concentration of Dhaka city. We include wind direction components as predictors in the model in addition to temperature, rainfall or precipitation, relative humidity, solar radiation, and wind speed. We develop two sets of models - one to predict $\mathrm{PM}_{2.5}$ concentration and the other to predict $\mathrm{PM}_{2.5-10}$ (particles with an aerodynamic diameter in between 2.5 and $10 \mu \mathrm{m}$ ) concentration-using the available data of an air quality monitoring station in Dhaka. We also evaluate the model performance by incorporating first-order interaction terms between the meteorological parameters and the previous day's PM concentrations as potential predictors. Additionally, we quantify the relative contribution of significant meteorological parameters and PM lag to the variation in 24-hour average PM concentration. Finally, we validate our prediction models by applying them to a recent dataset of the same monitoring site. We also assess the performance of the model in explaining spatial variability by employing it in two other monitoring stations of Dhaka.

\section{METHODS}

\subsection{The Study Area and Data Source}

This study analyzed air quality and meteorology data of Dhaka measured at Continuous Air Monitoring Stations (CAMSs). CAMSs record hourly PM data using Met One Model beta attenuation monitor (BAM)-1020, which is a U.S. Environmental Protection Agency Federal Equivalent Method (FEM) monitor (Mahmood et al., 2019). CAMS also measures meteorological parameters including rainfall, temperature, relative humidity, solar radiation, wind speed, and direction. CAMS data are reported monthly by the Department of Environment (DoE), Bangladesh. Dhaka has three CAMSs (Fig. S1) located at Sangshad Bhaban, Sher-e-Bangla Nagar (CAMS-1); Farmgate (CAMS-2); and Darus-Salam, Mirpur (CAMS-3). CAMS-1 is an urban air monitoring site that started operation in April 2002 and is located close to two major roads with heavy traffic congestion: Rokeya Sharani ( 150 meters) and Manik Mia Avenue ( 300 meters). The second CAMS is also an urban monitor located on the premises of the Bangladesh Agricultural Research Council (BARC) to capture the pollution from the busy Farmgate area. CAMS-3 is located at around $100 \mathrm{~m}$ from a traffic-congested Mirpur road and near major brick kiln clusters. CAMS-2 started monitoring data since June 2008, while CAMS-3 started reporting data from November 2012 (Afrin et al., 2012).

We collected the daily PM $\left(\mathrm{PM}_{2.5}\right.$ and $\left.\mathrm{PM}_{10}\right)$ and meteorological data of CAMS- 1 for the $1^{\text {st }}$ three years (April 2002-May 2004) of its operation, and developed a meteorology based 
statistical model of PM using this dataset. We used a recent dataset of CAMS-1 from 2013 to 2017 for model validation. We also used the 2013-2017 data of the other two CAMSs for the models' spatial validation. For the analysis, we split the total $\mathrm{PM}_{10}$ concentrations into two size fractions: the finer fraction $\left(\mathrm{PM}_{2.5}\right)$ and the coarser fraction $\left(\mathrm{PM}_{2.5-10}\right)$. We used daily average atmospheric temperature $(T)$, rainfall $(R)$, relative humidity $(R H)$, and solar radiation (SR), wind speed (WS), and two components of wind direction (WD): North-South (Cosine of WD) and EastWest (Sine of WD). The daily variations of PM fractions and meteorological parameters at CAMS1 for a typical winter month (February 2015) are shown in Fig. S2 and the summary statistics of all three CAMSs are presented in Table S1. PM concentrations and meteorological parameters show day-to-day variation over a month with no consistent weekday versus weekend trend. While the daily variation in PM fractions $\left(\mathrm{PM}_{2.5}\right.$ and $\left.\mathrm{PM}_{2.5-10}\right)$ seem to follow a similar trend with peaks and falls at the same time (day) of the month, we do not observe any consistent trend among the meteorological variables (Fig. S2).

\subsection{Model Development and Validation}

In this study, we used multiple regression to develop generalized linear models of PM fractions $\left(\mathrm{PM}_{2.5}\right.$ and $\mathrm{PM}_{2.5-10}$ ). We applied the traditional regression approach (model having all predictors included) and several stepwise approaches (forward selection, backward elimination, and bidirectional) to our data and calculated adjusted $R^{2}$ and Akaike information criterion (AIC) values of each model as adjusted $\mathrm{R}^{2}$ and $\mathrm{AIC}$ are frequently used to assess the relative performance of models (Wang et al., 2018; Han et al., 2019). In stepwise regression, the choice of predictive variables was carried out considering forward, backward, or both-way selections of variables depending on the approaches. The final model only retained the significant predictors based on the $p$-value for the $\mathrm{F}$ or chi-squared test of the change in the deviance by adding or removing the term. In our analysis, we defined a significance level of $p<0.05$. We tested assumptions of normality, independence of errors, and collinearity using the probability plots, "Durbin-Watson" test and "variance inflation factor (VIF)" respectively. Assumptions of linearity and homogeneity of variances were also checked with Residuals-Fits plots.

Initially, we simulated a set of models including only linear terms of the meteorological variables, $x_{i}$ (Eq. (1)). To assess the influence of the interaction between these meteorological variables in explaining the variability of the PM model, we developed a second set of models including both linear terms $\left(x_{i}\right)$ and first-order interactions between these meteorological variables $\left(x_{i} x_{j}\right)$ as potential predictors (Eq. (2)). In addition, we developed another set of models appending the lag PM concentrations to the linear and interaction terms of the meteorological variables (Eq. (3)) to explore the possible lag effect of PM.

$$
\begin{aligned}
& \mathrm{PM}=\beta_{0}+\sum_{i=1}^{7} \beta_{i} x_{i} \\
& \mathrm{PM}=\beta_{0}+\sum_{i=1}^{7} \beta_{i} x_{i}+\sum_{i=1}^{6} \sum_{j=i+1}^{7} \beta_{i j} x_{i} x_{j} \\
& \mathrm{PM}=\beta_{0}+\beta_{l} \text { lag PM }+\sum_{i=1}^{7} \beta_{i} x_{i}+\sum_{i=1}^{6} \sum_{j=i+1}^{7} \beta_{i j} x_{i} x_{j}
\end{aligned}
$$

In these equations, $\mathrm{PM}$ could be either 24-hour average $\mathrm{PM}_{2.5}$ or $\mathrm{PM}_{2.5-10}$ during the study period considered, $\boldsymbol{\beta}_{0}$ is the intercept term, $\boldsymbol{\beta}_{1}$ is the regression coefficient for lag PM term, and $\boldsymbol{\beta}_{i}$ and $\boldsymbol{\beta}_{i j}$ are the regression coefficients for meteorological variables $(x)$.

Further, we quantified the relative importance of the weather predictors and PM lag in the regression models by applying the average increment method (Tonidandel and LeBreton, 2011). This method follows the principle of dominance analysis (Azen and Budescu, 2003) to calculate the shared variance by individual predictors to the total variance or explaining power of a model. Finally, the PM regression models developed using CAMS-1's earlier dataset (2002-2004) was validated with its recent dataset (2013-2017). We applied daily meteorological data from 2013 
to 2017 on the models to calculate modeled PM and compare it with observed 24-hour average PM for validation. We also applied the recent dataset of two other CAMSs ( 2 and 3 ) in the models to assess their spatial validity. In this validation process, we used the Pearson correlation coefficient or "r-value"to measure how strong the correlation is between observed and modeled PM concentrations. We also calculated normalized mean error (NME) and normalized mean bias (NMB) to assess the performance of the models (Appel et al., 2011). To investigate the influence of seasonality in the model-vs-measurement comparison, we divided the yearly data into two characteristic seasons in Bangladesh based on rainfall pattern: dry-season (October-March) and wet-season (April-September) (Islam et al., 2015). We further divided each of these two seasons into two quarterly periods (dry-period: January-March (JFM), October-December (OND); and wet-period: April-June (AMJ), July-September (JAS)) during the model validation process to discern quarterly trend. In addition, we conducted monthly validation of models and assessed the weekday versus weekend influence in model performance.

\section{RESULTS AND DISCUSSION}

\subsection{PM Regression Models with Linear Terms Only}

The significant predictors with coefficients $(\beta)$ of $\mathrm{PM}_{2.5}$ and $\mathrm{PM}_{2.5-10}$ models for different multilinear regression approaches along with respective adjusted $\mathrm{R}^{2}$ and $\mathrm{AIC}$ values are summarized in Table S2. In general, adjusted $\mathrm{R}^{2}$ and AIC values of models obtained for different approaches are close to each other. For the $\mathrm{PM}_{2.5}$ model, a backward elimination approach provides the largest adjusted $\mathrm{R}^{2}$ with the lowest AIC value, while for the $\mathrm{PM}_{2.5-10}$ model, all three stepwise approaches yield the same result. Hence, we consider the model from the backward elimination approach for the rest of the discussion in this paper and tabulate the summary statistics of its outcome in Table 1.

As illustrated in Table 1, the $\mathrm{PM}_{2.5}$ model can explain $57 \%$ variability of daily $\mathrm{PM}_{2.5}$ concentrations. Temperature, relative humidity, and wind parameters appear as significant predictors for the $\mathrm{PM}_{2.5}$ model. The negative association between $\mathrm{PM}_{2.5}$ and $\mathrm{RH}$ can be explained by the growth and subsequent wet deposition of particles. Several studies (Islam et al., 2015, 2018; Kayes et al., 2019) also observed a similar effect of $\mathrm{RH}$ on $\mathrm{PM}_{2.5}$. The inverse relationship between $\mathrm{T}$ and $\mathrm{PM}_{2.5}$ is common in literature (Wang et al., 2013) and likely indicates the cooling effect of PM due to its net negative radiative forcing (Islam et al., 2015). Temperature was observed to be positively associated with planetary boundary layer (PBL) height and thus can reduce the $\mathrm{PM}_{2.5}$ concentrations by increasing the PBL height as well as pollutant dispersion. The T-PM 2.5 negative association can also be linked to seasonal variation of PM of Dhaka, which shows higher PM levels in dry winter months (October-March) compared to wet warmer months (April-September) (Islam et al., 2015). Wind speed shows a negative relation with $\mathrm{PM}_{2.5}$ indicating the probable dispersion and subsequent dilution of particle concentration in the air due to wind speed (Islam et al., 2018). The positive association of PM with the North-South component of wind speed (CosWD) suggests that $\mathrm{PM}_{2.5}$ concentrations increase when winds come from north directions.

Table 1. Significant parameters of the PM backward elimination regression models considering only the linear terms of meteorological parameters as predictor variables.

\begin{tabular}{|c|c|c|c|c|c|c|c|c|}
\hline $\begin{array}{l}\text { Response variables } \\
\text { (PM) }\end{array}$ & $\begin{array}{l}\text { Predictor } \\
\text { variable }(x)\end{array}$ & $\begin{array}{l}\text { Estimate } \\
(\beta)\end{array}$ & $\begin{array}{l}\text { Standard Error } \\
(\mathrm{SE})\end{array}$ & t-statistics & P-value & VIF & $\begin{array}{l}\text { Durbin- } \\
\text { Watson }\end{array}$ & $\begin{array}{l}\text { Adjusted } \\
\mathrm{R}^{2}\end{array}$ \\
\hline \multirow[t]{6}{*}{$\mathrm{PM}_{2.5}$} & Intercept & 416.86 & 34.1 & 12.23 & $2 \mathrm{E}-28$ & & \multirow{6}{*}{0.95} & \multirow{6}{*}{0.57} \\
\hline & $\mathrm{T}$ & -8.39 & 0.75 & -11.26 & $6 \mathrm{E}-25$ & 1.9 & & \\
\hline & $\mathrm{RH}$ & -1.2 & 0.3 & -3.95 & $1 \mathrm{E}-04$ & 1.2 & & \\
\hline & WS & -11.41 & 3.24 & -3.52 & $5 \mathrm{E}-04$ & 1.1 & & \\
\hline & SinWD & -10.08 & 5.13 & -1.96 & $5 \mathrm{E}-02$ & 1.3 & & \\
\hline & CosWD & 11.98 & 4.17 & 2.87 & $4 \mathrm{E}-03$ & 1.7 & & \\
\hline \multirow[t]{3}{*}{$\mathrm{PM}_{2.5-10}$} & Intercept & 298.8 & 18.06 & 16.55 & $8 \mathrm{E}-45$ & & \multirow{3}{*}{1.1} & \multirow{3}{*}{0.35} \\
\hline & $\mathrm{T}$ & -2.51 & 0.38 & -6.62 & $2 \mathrm{E}-10$ & 1.0 & & \\
\hline & $\mathrm{RH}$ & -2.27 & 0.2 & -11.57 & $5 \mathrm{E}-26$ & 1.0 & & \\
\hline
\end{tabular}


This finding is in the line with earlier literature (Islam et al., 2015; Mahmood et al., 2019) where winds coming from north-west direction were found to transport particles to Dhaka from the major brick-kiln clusters located there. The negative association of $\mathrm{PM}_{2.5}$ with the East-West wind direction (SinWD) suggests that winds coming from this direction drive particles away from the city. These findings highlight the potential role of wind direction as a model predictor, which has not been explored by previous air quality studies in Dhaka (Islam et al., 2018; Kayes et al., 2019).

The $\mathrm{PM}_{2.5-10}$ regression model shows lower predictive power (Adjusted $R^{2}=0.35$ ) than that of the $\mathrm{PM}_{2.5}$ model (Table 1), suggesting that meteorology has less influence over coarser PM fraction than the finer fraction in Dhaka. Like the $\mathrm{PM}_{2.5}$ model, $\mathrm{T}$ and $\mathrm{RH}$ are the significant predictors of the $\mathrm{PM}_{2.5-10}$ model, and their negative associations with $\mathrm{PM}_{2.5-10}$ are comparable to other studies (Islam et al., 2015). However, the wind speed and direction do not appear to be significant predictors in the $\mathrm{PM}_{2.5-10}$ model indicating that particle transportation by winds to and from Dhaka has less influence on the coarser fraction than the finer one.

\subsection{Quantification of the Relative Contribution of Model Parameters}

The t-Statistics (absolute value) presented in Table 1 indicates the comparative contribution of different predictors to explain model variability. For the $\mathrm{PM}_{2.5}$ model, $\mathrm{T}$ has a higher contribution than the other significant predictors, whereas, for the $\mathrm{PM}_{2.5-10}$ model, RH has a higher influence. Using dominance analysis, we further quantify the proportional contribution of each predictor to the total variability explained by the models. Fig. 1 represents the total variability as well as the shared variability explained by the significant meteorological parameters influencing the PM concentration. For the $\mathrm{PM}_{2.5}$ model, $\mathrm{T}$ can explain $58 \%$ of the total variability, whereas WS and WD together can explain $38 \%$ variability. Although $\mathrm{RH}$ has a small influence on $\mathrm{PM}_{2.5}$, it explains $72 \%$ of the total variability of coarser particles with the rest of the variability explained by temperature.

\subsection{Validation of Models}

As mentioned earlier, we validate the $\mathrm{PM}_{2.5}$ and $\mathrm{PM}_{2.5-10}$ regression models of CAMS-1 using its recent dataset. Fig. 2 depicts the outcomes of the validation process. Fig. 2(a) shows the time series plots of 24-hour average observed and modeled PM $_{2.5}$ concentrations at CAMS-1 for the 2013-2017 period. Note that, CAMS-1 does not have observed data for the entire 2016 and early dry months (up to March) of 2017. In addition, data are not available for the $50 \%$ days of the remaining period between 2013 and 2017. Fig. 2(a) exhibits a distinct seasonal variation of observed $\mathrm{PM}_{2.5}$ with high concentrations during the dry season. Modeled $\mathrm{PM}_{2.5}$ follows the observed $\mathrm{PM}_{2.5}$ over the seasons indicating the model's ability to capture the seasonal variability. A strong and significant positive correlation coefficient $(r=0.81)$ between observed and modeled datasets (Fig. 2(b)) also verifies the model's ability to predict ambient $\mathrm{PM}_{2.5}$ concentration from the meteorological variables considered. However, the model does not seem to capture some low concentration events during the wet season.

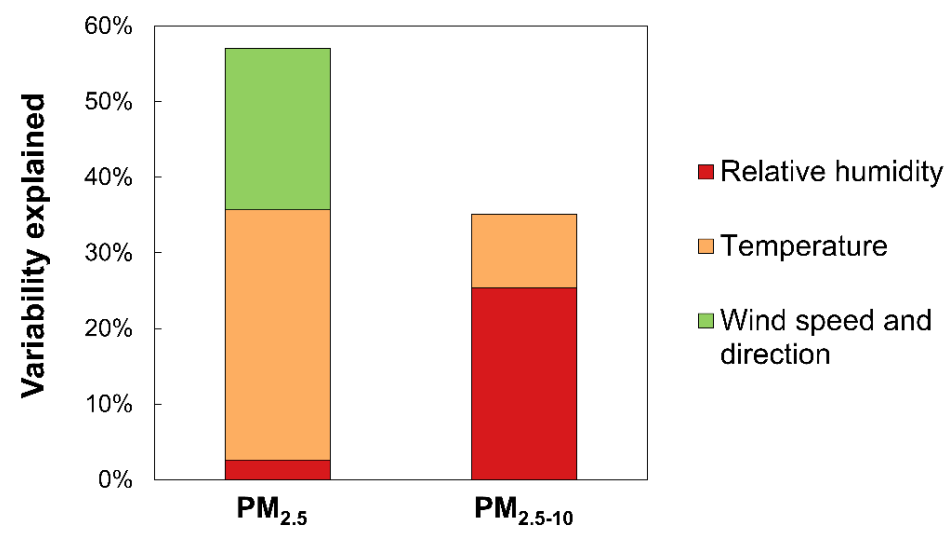

Fig. 1. The relative contribution of the considered meteorological variables in explaining the total variability. 
(a)

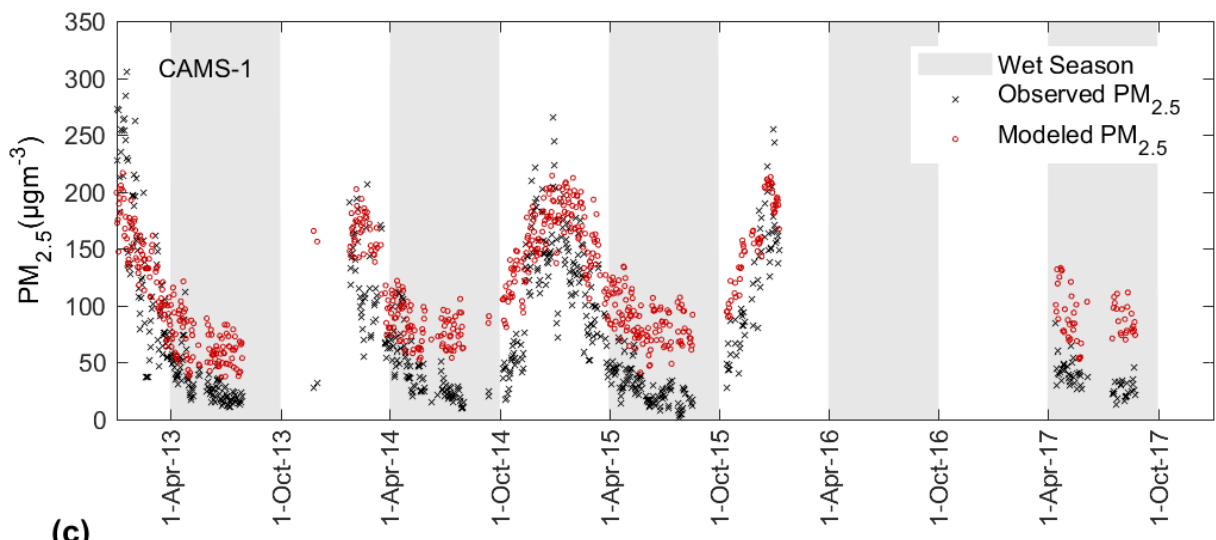

(c)

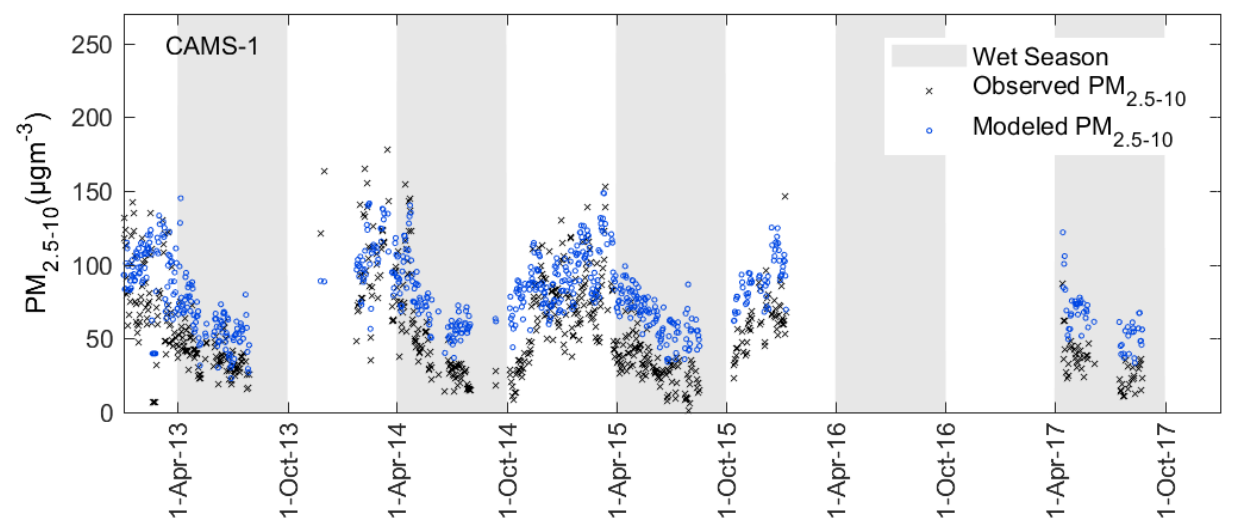

(b)

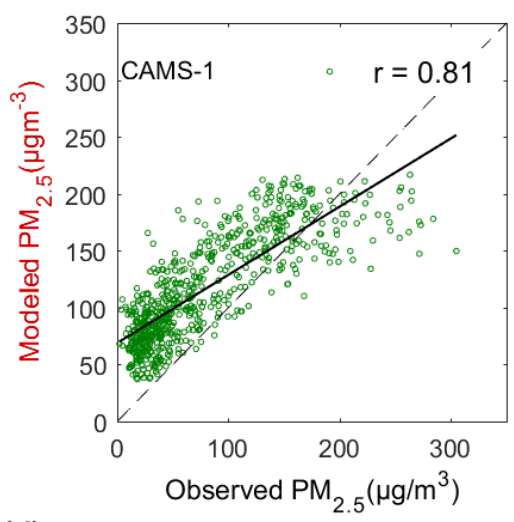

(d)

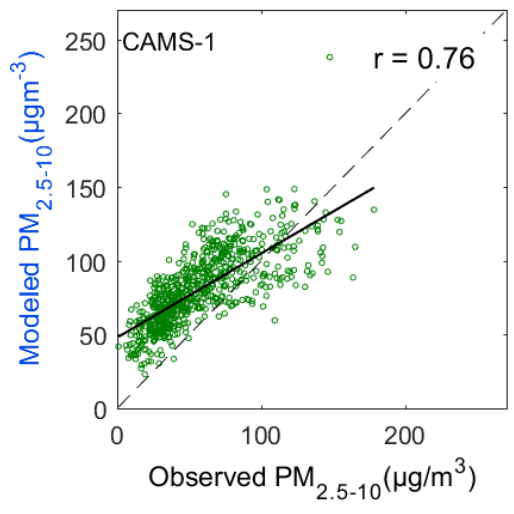

Fig. 2. Comparison of observed and modeled 24-hr average PM concentrations at CAMS-1. The left panels show the time series plots of modeled and observed (a) PM2.5 concentrations, and (c) PM2.5-10 concentrations. The typical wet seasons (AprilSeptember) are shown in grey shading. The right panels show the correlation coefficient between observed and modeled(b) $\mathrm{PM}_{2.5}$ concentrations, and (d) $\mathrm{PM}_{2.5}$ concentrations respectively.

This observation led us to assess the model's performance at yearly, seasonal, quarterly, and monthly bases. Table S3 summarizes the different performance indicators (e.g., NMB, NME, r-value, and associated $\mathrm{p}$-values) at those time bases. The yearly evaluation shows a consistently strong correlation between the modeled and measured $\mathrm{PM}_{2.5}$ concentrations from 2013-2015 ( $\left.r>0.80\right)$. Insufficient sample sizes in 2016 and 2017 ( 9 and 55 data points respectively) do not allow assessing model performance, which is also reflected by the statistical insignificance ( $p$-value > 0.05 ) in correlations in those years. In terms of NMB and NME, yearly model evaluations also show promise. For example, NME values for the 2013-2015 time period range from $49 \%$ to $68 \%$, which are below 75\% - one of the NME thresholds used in model evaluation process (Appel et al., 2011). Similarly, NMB values, ranging from $24 \%$ to $65 \%$, are also either below or close to a corresponding NMB threshold of $60 \%$ (Appel et al., 2011).

The season-wise validation of models reveals an interesting fact (Table S3). The model seems to predict $\mathrm{PM}_{2.5}$ concentrations better in dry season than wet season as evidenced by the NME, $\mathrm{NMB}$, and $r$-values. While NMB and NME values for the dry season are below the respective thresholds mentioned above, these values are much higher than the thresholds during the wet season. Correlation between measured and modeled $\mathrm{PM}_{2.5}$ is also stronger during the dry season $(r=0.63)$ relative to wet season $(r=0.38)$. Quarterly evaluation of model performance also indicates better performance of models during the dry season than that of wet season. The two quarters of the wet season (AMJ and JAS) have higher NME, NMB values than the thresholds, and lower correlation coefficients than those of dry season. This finding is also evident from the time series plot of modeled and observed PM concentrations of a representative year covering two dry quarters and two wet quarters from October 2014 to September 2015 (Fig. 3).

NME and NMB values of monthly evaluation are shown in a soccer plot (Fig. 4) and tabulated 
(a)

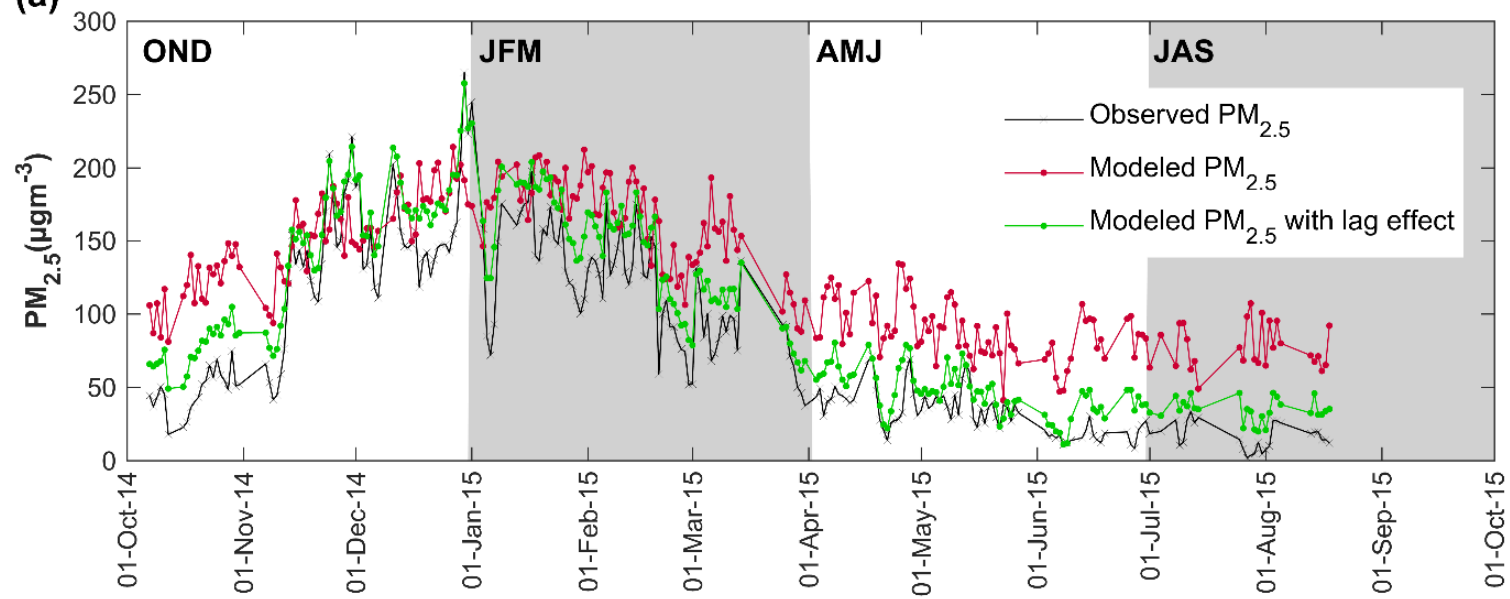

(b)

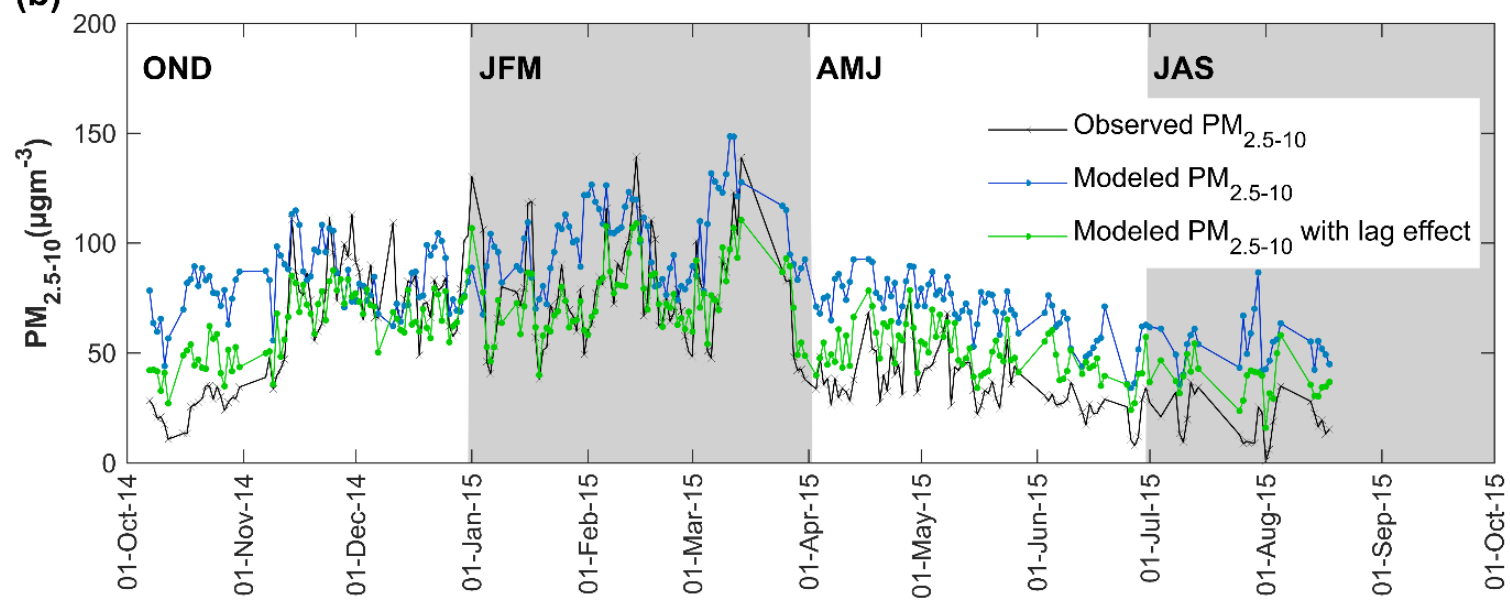

Fig. 3. Variation of observed and modeled 24-hr average PM concentrations at CAMS-1 with and without the lag effect of previous day's PM. This figure covers the time series plots of a typical dry (October-March) and a wet (April-September) season from October-2014 to September-2015 for (a) PM2.5 concentrations and (b) PM2.5-10 concentrations. The three-monthly quarters (JFM, AMJ, JAS, and OND) are also highlighted by alternate grey shades.

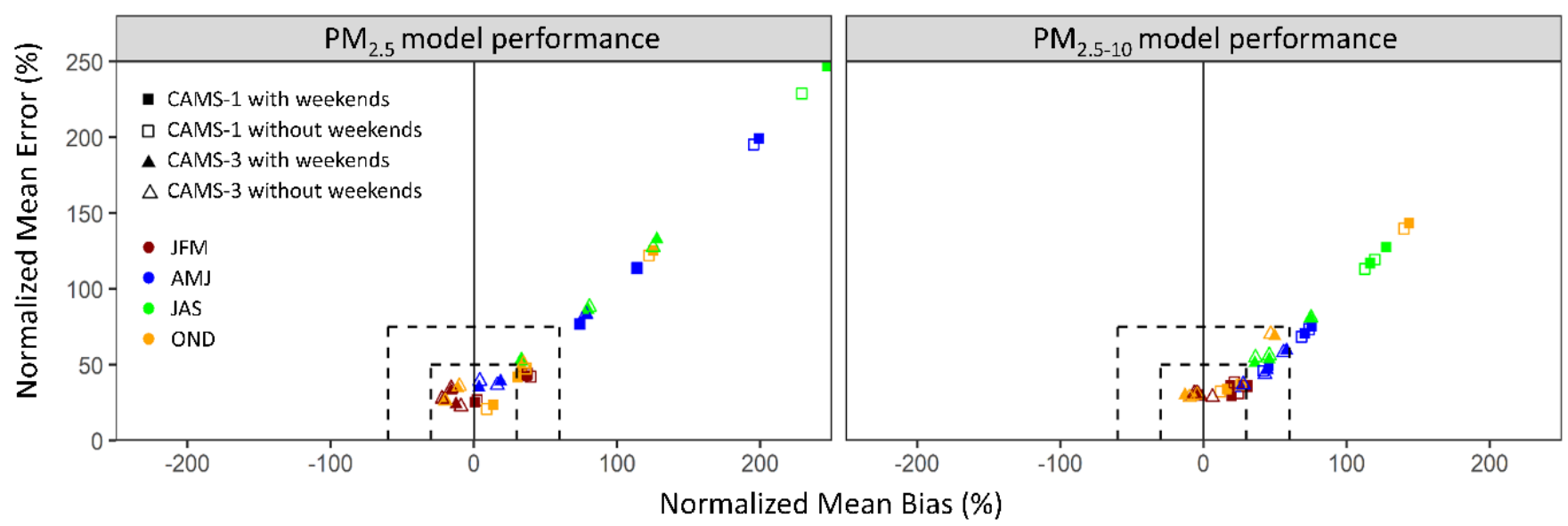

Fig. 4. Soccer plot for $P M_{2.5}$ and $P M_{2.5-10}$ models performance evaluation. Each data point is representing the model's performance evaluation statistics by month. For each month, statistics based on data of CAMS-1 and CAMS-3 are shown separately as rectangular and triangular markers respectively. Again, for a specific CAMS, the filled markers are presenting the statistics when all available data points from 2013 to 2017 under that month are considered in the analysis, while the empty markers are presenting the statistics when data points excluding the weekends are considered. These data points are further colored by their corresponding quarters (JFM, AMJ, JAS, and OND). 
in Table S3. NMB and NME values of all dry months (except October) lie within or close to the goal bar enclosed by $\pm 30 \%$ NMB and $50 \%$ NME values, whereas wet months are even outside the bar enclosed by $\pm 60 \%$ NMB and $75 \%$ NME. Note that on soccer plots, percentages of NME and NMB close to zero indicate better model performance compared to the bars further away. This observation restates the fact that model predicts $\mathrm{PM}_{2.5}$ concentration better in dry months relative to wet months. Interestingly, the correlations between the modeled and measured $\mathrm{PM}_{2.5}$ concentration at monthly levels are weaker than those for the previous time bases and we observe a gradual decrease in $r$-values as we move down from yearly to smaller time bases (e.g. yearly > seasonal > quarterly > monthly). Overall, the positive NMB beyond the considered threshold for the time bases of wet-season illustrates that the model is overestimating $\mathrm{PM}_{2.5}$ concentration during wet summer months at CAMS-1. Model performance matrices for CAMS-3 is also evaluated and presented in Fig. 4.

Like PM 2.5 , the time series plot of observed PM2.5-10 in CAMS-1 (Fig. 2(c)) shows seasonal variation, and the model seems to capture the variability. The strong positive correlation $(r=0.76)$ between the modeled and observed $\mathrm{PM}_{2.5-10}$ exhibits a promising performance of the model in predicting coarser PM fractions. However, similar to $\mathrm{PM}_{2.5}$, the $\mathrm{PM}_{2.5-10}$ model mostly overestimates the observed values during the wet months, and hence, we validate the model performance on different time bases (e.g., yearly, seasonal, quarterly, and monthly). A summary of this validation process is shown in Table S4. NMB and NME values associated with the yearly evaluation range from 30 to $55 \%$ and 41 to 58\% respectively (excluding 2016 and 2017 due to insufficient sample size), which are below the $60 \% \mathrm{NMB}$ and $75 \%$ NME thresholds. Yearly correlation coefficients between the observed and modeled $\mathrm{PM}_{2.5-10}$ concentrations are also high $(r>0.70, p<0.05)$, suggesting consistent model performance throughout the evaluation period. Seasonal and quarterly evaluations indicate better model performance in the dry season than the wet season, similar to $\mathrm{PM}_{2.5}$. The monthly evaluation of $\mathrm{PM}_{2.5-10}$ model displays better performance in terms of bias and error than that of the $\mathrm{PM}_{2.5}$ model as shown in the soccer plot (Fig. 4). However, for both models ( $\mathrm{PM}_{2.5}$ and $\mathrm{PM}_{2.5-10}$ ), NMB and NME values of all dry months (except October) lie within the $\pm 30 \% \mathrm{NMB}$ and $50 \%$ NME limit, whereas wet months remain outside the $\pm 60 \% \mathrm{NMB}$ and $75 \%$ NME limit. During the monthly model validation, we also explore the weekday versus weekend effect on model performance by calculating the bias and error values excluding the weekends. The resulting NMB and NME values are also shown in the soccer plots (Fig. 4). We do not observe any substantial and consistent change in model (both $\mathrm{PM}_{2.5}$ and $\mathrm{PM}_{2.5-10}$ ) performances due to the weekday-weekend effect, suggesting that differences in activities between the weekdays and weekends do not play a major role in model performance for the study area.

\subsection{Model Application to Other Monitoring Sites}

We apply CAMS-1 PM regression models to CAMS-2 and CAMS-3 to test its spatial validity within Dhaka. Using the meteorological data of CAMS-2 and CAMS-3, we calculate PM concentrations employing the CAMS-1 regression models. A comparison between modeled and observed PM demonstrates its applicability to other locations within Dhaka. Figs. S3(a) and S3(c) show the time series plots of observed and modeled $\mathrm{PM}_{2.5}$ concentrations at CAMS-3 and CAMS-2 respectively. CAMS-3 has 64\% daily data available between 2013 and 2017, whereas CAMS-2 has representative data in 2013 only. For the rest of the period in CAMS-2, data is either missing or having a recording issue (e.g., $\mathrm{PM}_{2.5}$ is higher than $\mathrm{PM}_{10}$ ). Similar to CAMS-1, modeled $\mathrm{PM}_{2.5}$ seems to follow the observed $\mathrm{PM}_{2.5}$ in both CAMSs. The positive correlation between the observed and modeled $\mathrm{PM}_{2.5}$ in CAMS-3 is as strong $(r=0.81)$ as CAMS-1 (Fig. S3(b)). However, the model seems to start underestimating the observed data at a lower concentration $\left(100 \mu \mathrm{g} \mathrm{m}^{-3}\right)$ in CAMS-3 relative to CAMS-1 $\left(180 \mu \mathrm{g} \mathrm{m}^{-3}\right)$. Monthly NMB and NME values are, in general, lower for CAMS-3 data relative to CAMS-1 data (Fig. 4), indicating the promising performance of the model developed by CAMS-1 data in predicting PM concentrations in the CAMS-3 area. For CAMS-2, the association between observed and modeled $\mathrm{PM}_{2.5}$ concentration $(r=0.61)$ is not as strong as the other two CAMSs, possibly due to having limited data points (Figs. S3(c) and S3(d)). The model mostly overestimates the available observed data over the entire $\mathrm{PM}_{2.5}$ range. A scattered pattern is also observed for the modeled PM when observed $\mathrm{PM}_{2.5}$ concentration is below $50 \mu \mathrm{g} \mathrm{m}^{-3}$. Similar to $\mathrm{PM}_{2.5}$, the $\mathrm{PM}_{2.5-10}$ model works well for CAMS-3 in capturing the seasonality (Fig. S3(e)). The correlation between observed and modeled dataset is also strong $(r=0.73)$, and comparable to 
CAMS-1 (Figs. S3(f) and 2(d)). For CAMS-2, modeled PM2.5-10 is mostly higher than the observed, and shows a moderate association ( $r=0.60$ ) (Figs. S3(g) and S3(h)), similar to $\mathrm{PM}_{2.5}$.

\subsection{PM Regression Models with Interaction Terms}

Table 2 summarizes the PM models including interaction terms between considered meteorological parameters and reports the estimated intercept, regression coefficients of significant predictors, and adjusted- $\mathrm{R}^{2}$ of models. For the $\mathrm{PM}_{2.5}$ model, in addition to linear terms ( $T, R H, W S$ ), interaction between wind speed and wind direction component appears as a significant predictor and tends to reduce the concentration, consistent with the model without interactions. However, we do not see an increase in adjusted- $\mathrm{R}^{2}$ suggesting that model's predictive power remains the same. For $\mathrm{PM}_{2.5-10}$, the model does not change when interaction terms are included depicting the insignificant influence of meteorological interaction over coarse particles.

\subsection{PM Regression Models with Previous Day's Concentration}

The inclusion of previous day's PM concentration (PM lag effect) substantially increases the predictive power of fine and coarse PM models in explaining variability (Table 2). The PM2.5 model with PM lag effect can explain $16 \%$ more variability than the initial models with meteorological parameters only. By estimating the relative influence of the previous day's $\mathrm{PM}_{2.5}$ concentration in explaining the overall variability of the $\mathrm{PM}_{2.5}$ model (e.g., average increment method), we find that lag $\mathrm{PM}_{2.5}$ alone can explain $\sim 60 \%$ of the total explaining variability of the model, while meteorological variables explain the rest $40 \%$. Similar to the $\mathrm{PM}_{2.5}$ model, addition of previous day's coarse PM fraction increases the PM $_{2.5-10}$ model's explanatory power, but only by $4 \%$ relative to the model with meteorological variables. Consequently, PM concentrations from the model with lag effect show a stronger positive correlation with observed $\mathrm{PM}_{2.5}$ concentrations at CAMSs than that of the model without the lag. For instance, at CAMS-1, the estimated Pearson correlation coefficients between observed and modeled (with lag PM) concentrations between

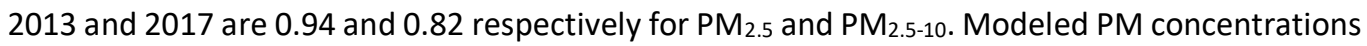
also seem to capture the peak and fall of the observed PM more representatively relative to the model without the lag (Fig. 3). This is also reflected by the lower NMB and NME values of PM models with lag-effect relative to model without lag PM. For example, NME and NMB values of the $\mathrm{PM}_{2.5}$ model with lag are $25 \%$ and $17 \%$ respectively (2013-2017), which are substantially lower than those for the model without lag (59\% and $48 \%$ respectively). We also explore the model performance by varying the averaging window of lag PM concentrations. We replace the previous day's PM with the average of previous two days' PM concentrations as a predictor in

Table 2. Summary of stepwise (backward elimination) multilinear regression models of PM when interaction terms and PM lag are included as covariates.

\begin{tabular}{|c|c|c|c|c|}
\hline \multirow[b]{2}{*}{ Predictors* } & \multicolumn{2}{|c|}{$\mathrm{PM}_{2.5}$} & \multicolumn{2}{|c|}{$\mathrm{PM}_{2.5-10}$} \\
\hline & Interaction & $\begin{array}{l}\text { Interaction and } \\
\text { PM lag }\end{array}$ & Interaction & $\begin{array}{l}\text { Interaction and } \\
\text { PM lag }\end{array}$ \\
\hline Intercept & 409.63 & 158.51 & 298.80 & 71.38 \\
\hline $\mathrm{R}$ & - & - & - & 12.78 \\
\hline $\mathrm{T}$ & -8.29 & -4.24 & -2.51 & - \\
\hline $\mathrm{RH}$ & -1.14 & - & -2.27 & -0.54 \\
\hline SR & - & - & - & - \\
\hline WS & -11.53 & -11.75 & - & - \\
\hline SinWD & - & - & - & -9.82 \\
\hline CosWD & 12.14 & - & - & - \\
\hline WS*SinWD & -7.09 & - & - & - \\
\hline PM lag & NA & 0.65 & NA & 0.49 \\
\hline Adjusted $\mathrm{R}^{2}$ & 0.57 & 0.73 & 0.35 & 0.39 \\
\hline
\end{tabular}

* Table only lists the interaction terms that appeared significant ( $p$-value $<0.05$ ) in the models with no multi-collinearity. Predictors with no coefficients (represented by a horizontal dash: -) indicate that those did not appear significant in the respective model 1. 
the model to identify any changes in model performance. This new model does not show any increment in adjusted $\mathrm{R}^{2}$ from the previous model (Table S5). A model with previous three days' PM concentrations, instead of the previous day's PM, remains the same too (Table S5), indicating that lag PM concentrations beyond one day do not influence model performance for the study area.

\section{CONCLUSIONS}

This paper presents a simple statistical modeling framework for PM in Dhaka city. The models show substantial predictive power to forecast $\mathrm{PM}_{2.5}$ and $\mathrm{PM}_{2.5-10}$ concentrations from meteorological inputs. Important meteorological variables seem to explain $57 \%$ variability in $\mathrm{PM}_{2.5}$ concentration, whereas for $\mathrm{PM}_{2.5-10}$, it is 35\%, suggesting that finer PM fraction is influenced more by meteorology than the coarser fraction. Temperature and relative humidity were significant predictors for both fractions of PM. Wind speed and wind direction did not appear to have significant influences on the $\mathrm{PM}_{2.5-10}$ model, although wind parameters explained more than one-third of the total variability explained by the $\mathrm{PM}_{2.5}$ model. Validation of the models by a dataset, 11 years apart, reflects its robustness to capture temporal variability. In addition, the promising performance of the model even for two different monitoring sites of Dhaka indicates its ability to capture spatial variability within the city. These findings imply that the meteorology based air quality model developed for a monitoring site of Dhaka can also be applied to other sites.

The modeling framework presented here has other implications too. We can use these models to predict the impact of climate change on ambient PM concentrations of Dhaka, given the same emission scenario. For example, the model indicates a $21 \%$ decrease in daily $\mathrm{PM}_{2.5}$ levels in Dhaka for a $5 \%$ increase in considered meteorological parameters $(R, T, R H, S R$, and WS) due to climate change, if same emission scenario prevails. Note that, $5 \%$ increase in all meteorological parameters is unlikely and is used here for comparison purposes only. The models presented here, especially with PM lag effect, can also be used to generate PM forecast in Dhaka from weather prediction. In addition, PM concentrations can be predicted from this model for any location in the city if meteorology is known. We can also have a retrospective analysis of the PM trend of the city where PM concentration data were not reported or were missing for a certain period of interest.

The modeling framework presented here is developed based on daily meteorological and PM concentrations data, aiming to predict daily PM levels in Dhaka. A similar modeling approach can be applied to develop models for other air pollutants (e.g., $\mathrm{O}_{3}, \mathrm{NO}_{x}, \mathrm{SO}_{x}$ ). In this study, we were not able to develop hourly PM models due to the unavailability of reported hourly air quality and meteorological data. Hence, we recommend future studies to develop models that can predict hourly PM concentrations upon the availability of hourly data. Note that, the predictive power of the developed PM models is indicated by their respective adjusted $\mathrm{R}^{2}$ values, and the predictions will have uncertainty. Hence, predicted PM values should be used with extreme caution acknowledging the limitations. In addition, the model is based on air quality and meteorological data of Dhaka only, and hence cautions are needed against using it for other geographical locations where emission scenarios and meteorology are different.

Despite having some limitations as any other model, this model has policy implications too. For example, this model quantifies the contribution of wind speed and directions to ambient PM variability and thus restates the harmful effect of brick kiln clusters located in the north-west direction of Dhaka (Begum et al., 2011; Islam et al., 2015; Mahmood et al., 2019). This finding might convince policymakers to think about the relocation of brick kiln clusters and help them find suitable sites for the move out based on wind speeds and direction. This study will also make policymakers think twice before approving any air polluting industries in and around Dhaka city.

\section{SUPPLEMENTARY MATERIAL}

Supplementary data associated with this article can be found in the online version at https://doi.org/10.4209/aaqr.2020.07.0371 


\section{REFERENCES}

Afrin, S., Islam, M.M., Ahmed, T., Ali, M.A. (2014). The influence of meteorology on particulate matter concentration in the air of Dhaka City. 2nd International Conference on Advances in Civil Engineering 2014 (ICACE-2014).

Afrin, T., Ashraf Ali, M., Rahman, S.M., Wadud, Z. (2012). Development of a grid-based emission inventory and a source-receptor model for Dhaka City. The U.S. EPA's International Emissions Inventory Conference (pp. 1-14), Hyatt Regency in Tampa, Florida, USA, 2012.

Appel, K.W., Gilliam, R.C., Davis, N., Zubrow, A., Howard, S.C. (2011). Overview of the atmospheric model evaluation tool (AMET) v1.1 for evaluating meteorological and air quality models. Environ. Modell. Software 26, 434-443. https://doi.org/10.1016/j.envsoft.2010.09.007

Azen, R., Budescu, D.V. (2003). The dominance analysis approach for comparing predictors in multiple regression. Psychol. Med. 8, 129-148. https://doi.org/10.1037/1082-989X.8.2.129

Bae, S., Hong, Y.C. (2018). Health effects of particulate matter. J. Korean Med. Assoc. 61, 749755. https://doi.org/10.5124/jkma.2018.61.12.749

Begum, B.A., Biswas, S.K., Hopke, P.K. (2006). Impact of banning of two-stroke engines on airborne particulate matter concentrations in Dhaka, Bangladesh. J. Air Waste Manage. Assoc. 56, 85-89. https://doi.org/10.1080/10473289.2006.10464430

Begum, B.A., Biswas, S.K., Markwitz, A., Hopke, P.K. (2010). Identification of sources of fine and coarse particulate matter in Dhaka, Bangladesh. Aerosol Air Qual. Res. 10, 345-353. https://doi.org/10.4209/aaqr.2009.12.0082

Begum, B.A., Biswas, S.K., Hopke, P.K. (2011). Key issues in controlling air pollutants in Dhaka, Bangladesh. Atmos. Environ. 45, 7705-7713. https://doi.org/10.1016/j.atmosenv.2010.10.022

Begum, B.A., Hopke, P.K., Markwitz, A. (2013). Air pollution by fine particulate matter in Bangladesh. Atmos. Pollut. Res. 4, 75-86. https://doi.org/10.5094/APR.2013.008

Begum, B.A., Hopke, P.K. (2018). Ambient air quality in Dhaka Bangladesh over two decades: Impacts of policy on air quality. Aerosol Air Qual. Res. 18, 1910-1920. https://doi.org/10.4209/ aaqr.2017.11.0465

Biswas, S.K., Tervahattu, H., Kupiainen, K., Khaliquzzaman, M. (2003). Impact of unleaded gasoline introduction on the concentration of lead in the air of Dhaka, Bangladesh. J. Air Waste Manage. Assoc. 53, 1355-1362. https://doi.org/10.1080/10473289.2003.10466299

Choi, J., Fuentes, M., Reich, B.J. (2009). Spatial-temporal association between fine particulate matter and daily mortality. Comput. Stat. Data Anal. 53, 2989-3000. https://doi.org/10.1016/ j.csda.2008.05.018

Cobourn, W.G. (2010). An enhanced PM$_{2.5}$ air quality forecast model based on nonlinear regression and back-trajectory concentrations. Atmos. Environ. 44, 3015-3023. https://doi.org/10.1016/j.atmosenv.2010.05.009

Cohen, A.J., Brauer, M., Burnett, R., Anderson, H.R., Frostad, J., Estep, K., Balakrishnan, K., Brunekreef, B., Dandona, L., Dandona, R., Feigin, V., Freedman, G., Hubbell, B., Jobling, A., Kan, H., Knibbs, L., Liu, Y., Martin, R., Morawska, L., ... Forouzanfar, M.H. (2017). Estimates and 25-year trends of the global burden of disease attributable to ambient air pollution: An analysis of data from the Global Burden of Diseases Study 2015. Lancet. 389, 1907-1918. https://doi.org/10.1016/S0140-6736(17)30505-6

Han, X., Li, H., Liu, Q., Liu, F., Arif, A. (2019). Analysis of influential factors on air quality from global and local perspectives in China. Environ. Pollut. 248, 965-979. https://doi.org/10.1016/j. envpol.2019.02.096

Health Effects Institute (2017). State of Global Air 2017, A Special Report on Global Exposure to Air Pollution and Its Disease Burden. Health Effects Institute. https://ccacoalition.org/en/ resources/state-global-air-2017-special-report-global-exposure-air-pollution-and-its-diseaseburden (accessed 28 February 2020).

Health Effects Institute (2019). State of Global Air 2019. Special Report. Boston, MA: Health Effects Institute. https://www.stateofglobalair.org/sites/default/files/soga_2019_report.pdf (accessed 28 February 2020).

Hossain, K.M.A., Easa, S.M. (2012). Pollutant dispersion characteristics in Dhaka city, Bangladesh. ASIA-PAC. J. Atmos. Sci. 48, 35-41. https://doi.org/10.1007/s13143-012-0004-8 
Hossain, M.L., Roy, S.C., Bepari, M.C., Begum, B.A. (2019). Study of air quality at one of the world's most densely populated city dhaka and its suburban areas. J. Bangladesh Acad. Sci. 43, 59-66. https://doi.org/10.3329/jbas.v43i1.42234

IQAir (2018). 2018 World Air Quality Report PM2.5 Ranking. 2018 World Air Quality Report. https://www.airvisual.com/world-most-polluted-cities (accessed 28 February 2020).

Islam, A.M., Mohibullah, A., Paul, T. (2017). Cardiovascular disease in Bangladesh: A review. Bangladesh Heart J. 31, 80-99. https://doi.org/10.3329/bhj.v31i2.32379

Islam, M.M., Afrin, S. (2014). Air quality status of Dhaka City and effects of seasons, weekends, eid and hartal days. 2nd International Conference on Advances in Civil Engineering.

Islam, M.M., Afrin, S., Ahmed, T., Ali, M.A. (2014). The influence of meteorology on particulate matter concentration in the air of Dhaka City. 2nd International Conference on Advances in Civil Engineering 2014 (ICACE-2014).

Islam, M.M., Afrin, S. (2015). Riation of particulate matter the influence of brick kilns on seasonal var the influence of brick kilns on seasonal va iation of particulate matter concentration in Dhaka City. 11th International Conference on Mechanical Engineering, ICME 2015.

Islam, M.M., Afrin, S., Ahmed, T., Ali, M.A. (2015). Meteorological and seasonal influences in ambient air quality parameters of Dhaka city. J. Civ. Eng. 43, 67-77. https://jceieb.org/doc_file/4301006.pdf

Islam, N., Saroar, M.G., Ahmed, T. (2018). Meteorological influences on atmospheric particles in Darus Salam Area of Dhaka City. Proceedings of the 4th International Conference on Civil Engineering for Sustainable Development (ICCESD 2018), pp. 1-12, KUET, Khulna, Bangladesh. http://www.iccesd.com/proc_2018/Papers/r_p4167.pdf

Kayes, I., Shahriar, S.A., Hasan, K., Akhter, M., Kabir, M.M., Salam, M.A. (2019). The relationships between meteorological parameters and air pollutants in an urban environment. Global J. Environ. Sci. Manage. 5, 265-278. https://doi.org/10.22034/gjesm.2019.03.01

Konovalov, I.B., Beekmann, M., Meleux, F., Dutot, A., Foret, G. (2009). Combining deterministic and statistical approaches for $\mathrm{PM}_{10}$ forecasting in Europe. Atmos. Environ. 43, 6425-6434. https://doi.org/10.1016/j.atmosenv.2009.06.039

Leung, D.M., Tai, A.P.K., Mickley, L.J., Moch, J.M., Van Donkelaar, A., Shen, L., Martin, R.V. (2017). Synoptic meteorological modes of variability for fine particulate matter $\left(\mathrm{PM}_{2.5}\right)$ air quality in major metropolitan regions of China. Atmos. Chem. Phys. 18, 6733-6748. https://doi.org/10.5 194/acp-18-6733-2018

Liang, X., Zou, T., Guo, B., Li, S., Zhang, H., Zhang, S., Huang, H., Chen, S.X. (2015). Assessing Beijing's PM2.5 pollutions: Severity, weather impact, APEC and winter heating. Proc. R. Soc. London, Ser. A 471, 20150257. https://doi.org/https://doi.org/10.1098/rspa.2015.0257

Liu, Y., He, K., Li, S., Wang, Z., Christiani, D.C., Koutrakis, P. (2012). A statistical model to evaluate the effectiveness of $\mathrm{PM}_{2.5}$ emissions control during the Beijing 2008 Olympic Games. Environ. Int. 44, 100-105. https://doi.org/10.1016/j.envint.2012.02.003

Mahmood, A., Hu, Y., Nasreen, S., Hopke, P.K. (2019). Airborne particulate pollution measured in Bangladesh from 2014 to 2017. Aerosol Air Qual. Res. 19, 272-281. https://doi.org/10.4209/aa qr.2018.08.0284

Maji, K.J., Arora, M., Dikshit, A.K. (2018). Premature mortality attributable to PM2.5 exposure and future policy roadmap for 'airpocalypse' affected Asian megacities. Process Saf. Environ. Prot. 118, 371-383. https://doi.org/10.1016/j.psep.2018.07.009

Majumder, S., Sihabut, T., Saroar, M.G. (2019). Assessment of knowledge, attitude, and practices against inhaled particulate matter among urban residents in Dhaka, Bangladesh. J. Health Res. 33, 460-468. https://doi.org/10.1108/jhr-12-2018-0168

Marsha, A., Larkin, N.K. (2019). A statistical model for predicting PM2.5 for the western United States. J. Air Waste Manage. Assoc. 69, 1215-1229. https://doi.org/10.1080/10962247.2019.1 640808

Muntaseer Billah Ibn Azkar, M.A., Chatani, S., Sudo, K. (2012). Simulation of urban and regional air pollution in Bangladesh. J. Geophys. Res. 117, D07303. https://doi.org/10.1029/2011JD016509

Pearce, J.L., Beringer, J., Nicholls, N., Hyndman, R.J., Tapper, N.J. (2011). Quantifying the influence of local meteorology on air quality using generalized additive models. Atmos. Environ. 45, 1328-1336. https://doi.org/10.1016/j.atmosenv.2010.11.051

Price, O.F., Williamson, G.J., Henderson, S.B., Johnston, F., Bowman, D.M.J.S. (2012). The 
relationship between particulate pollution levels in Australian Cities, meteorology, and landscape fire activity detected from MODIS hotspots. PLoS One 7, e47327. https://doi.org/10. 1371/journal. pone.0047327

Rahman, M.M., Mahamud, S., Thurston, G.D. (2019). Recent spatial gradients and time trends in Dhaka, Bangladesh, air pollution and their human health implications. J. Air Waste Manage. Assoc. 69, 478-501. https://doi.org/10.1080/10962247.2018.1548388

Rana, M.M., Mahmud, M., Khan, M.H., Sivertsen, B., Sulaiman, N. (2016a). Investigating incursion of transboundary pollution into the atmosphere of Dhaka, Bangladesh. Adv. Meteorol. 2016, 8318453. https://doi.org/10.1155/2016/8318453

Rana, M.M., Sulaiman, N., Sivertsen, B., Khan, M.F., Nasreen, S. (2016b). Trends in atmospheric particulate matter in Dhaka, Bangladesh, and the vicinity. Environ. Sci. Pollut. Res. 23, 1739317403. https://doi.org/10.1007/s11356-016-6950-4

Salam, A., Hossain, T., Siddique, M.N.A., Shafiqul Alam, A.M. (2008). Characteristics of atmospheric trace gases, particulate matter, and heavy metal pollution in Dhaka, Bangladesh. Air Qual. Atmos. Health. 1, 101-109. https://doi.org/10.1007/s11869-008-0017-8

Tai, A.P.K., Mickley, L.J., Jacob, D.J. (2010). Correlations between fine particulate matter (PM2.5) and meteorological variables in the United States: Implications for the sensitivity of $\mathrm{PM}_{2.5}$ to climate change. Atmos. Environ. 44, 3976-3984. https://doi.org/10.1016/j.atmosenv.2010.06. 060

Tasmin, S., Ng, C.F.S., Stickley, A., Md, N., Saroar, G., Yasumoto, S., Watanabe, C. (2019). Effects of short-term exposure to ambient particulate matter on the lung function of school children in Dhaka, Bangladesh. Epidemiology 30, S15-S23. https://doi.org/10.1097/EDE.00000000000 01012

Thurston, G.D., Burnett, R.T., Turner, M.C., Shi, Y., Krewski, D., Lall, R., Ito, K., Jerrett, M,m Gapstur, S.M., Diver, W.r., Pope III, C.A. (2016). Ischemic heart disease mortality and long-term exposure to source-related components of U.S. fine Particle air pollution. Environ. Health Perspect. 124, 785-794. https://doi.org/10.1289/ehp.1509777

Tong, D., Geng, G., Jiang, K., Cheng, J., Zheng, Y., Hong, C., Yan, L., Zhang, Y., Chen, X., Bo, Y., Lei, Y., Zhang, Q., He, K. (2019). Energy and emission pathways towards $\mathrm{PM}_{2.5}$ air quality attainment in the Beijing-Tianjin-Hebei region by 2030. Sci. Total Environ. 692, 361-370. https://doi.org/1 0.1016/j.scitotenv.2019.07.218

Tonidandel, S., LeBreton, J.M. (2011). Relative importance analysis: a useful supplement to regression analysis. J. Bus. Psychol. 26, 1-9. https://doi.org/10.1007/s10869-010-9204-3

Wang, J., Wang, Y., Liu, H., Yang, Y., Zhang, X., Li, Y., Zhang, Y., Deng, G. (2013). Diagnostic identification of the impact of meteorological conditions on $\mathrm{PM}_{2.5}$ concentrations in Beijing. Atmos. Environ. 81, 158-165. https://doi.org/10.1016/j.atmosenv.2013.08.033

Wang, P., Guo, H., Hu, J., Kota, S.H., Ying, Q., Zhang, H. (2019). Responses of $\mathrm{PM}_{2.5}$ and $\mathrm{O}_{3}$ concentrations to changes of meteorology and emissions in China. Sci. Total Environ. 662, 297306. https://doi.org/10.1016/j.scitotenv.2019.01.227

Wang, S., Liu, X., Yang, X., Zou, B., Wang, J. (2018). Spatial variations of $\mathrm{PM}_{2.5}$ in Chinese cities for the joint impacts of human activities and natural conditions: A global and local regression perspective. J. Cleaner Prod. 203, 143-152. https://doi.org/10.1016/j.jclepro.2018.08.249

WHO (2016). World Health Statistics 2016, Monitoring Health for The SDGs, sustainable development goals, World Health Organization. https://www.who.int/gho/publications/world _health_statistics/2019/en/ (accessed 28 February 2020).

World Bank (2006). Bangladesh Country Environmental Analysis, Volume II: Technical Annex: Health Impacts of Air and Water Pollution in Bangladesh, Report No. 36945-BD, South Asia Environment and Social Development Unit, South Asia Region, The World Bank. http://documents.worldbank.org/curated/en/761171468002666985/pdf/3694510vol-02.pdf (accessed 28 February 2020).

Yao, J., Henderson, S.B. (2013). An empirical model to estimate daily forest fire smoke exposure over a large geographic area using air quality, meteorological, and remote sensing data. J. Exposure Sci. Environ. Epidemiol. 24, 328-335. https://doi.org/10.1038/jes.2013.87 